\title{
Synthesis and characterization of a novel quaternary copolymerized thermoplastic copolyimide with excellent heat resistance, thermoplasticity, and solubility
}

\author{
X. W. Cao, C. Wei, G. J. He , X. Liu
}

The Key Laboratory of Polymer Processing Engineering of Ministry of Education, Guangdong Provincial Key Laboratory of Technique and Equipment for Macromolecular Advanced Manufacturing, National Engineering Research Center of Novel Equipment for Polymer Processing, South China University of Technology, 510640 Guangzhou, China

Received 31 October 2019; accepted in revised form 21 January 2020

\begin{abstract}
A series of novel quaternary copolymerized thermoplastic polyimides were successfully prepared with asymmetric diahydride: 3,4'-oxydiphthalic anhydride (a-ODPA) and symmetric anhydride: 4,4'-oxydiphthalicanhydride (s-ODPA), 9,9'bis(4-aminophenyl)fluorene (BAFL) and 2,2-bis[4-(4-aminophenoxy)phenyl]propane (BAPP) as diamine. The synergistic effect of non-coplanar structure, fluorenyl cardo groups, methyl groups and flexible groups on the solubility, heat resistance and thermoplasticity of polyimide was discussed. The experimental results showed that the addition of BAFL greatly improved the heat resistance of polyimide. The glass transition temperature $\left(T_{\mathrm{g}}\right)$ of PI-A PI-E with different ratios were 235.3$305.5^{\circ} \mathrm{C}$. Compared with control group PI-F, PI-A PI-E were completely soluble within $3 \mathrm{~h}$ in DMF, DMAc, NMP, showing that they had excellent solubility, and what's more, under the synergistic effect, the thermoplasticity of PI-A PI-E was also greatly improved.
\end{abstract}

Keywords: tailor-made polymer, thermoplastic polyimide, non-coplanar structure, fluorene, thermal stability

\section{Introduction}

Owing to their excellent mechanical properties, thermal stability, solvent resistance and low dielectric properties, polyimides, especially aromatic polyimides are widely used in a broad variety of fields, in aerospace, photoelectric industry, military, microelectronics etc., [1-8]. However, the highly symmetric and rigid chemical structure of traditional aromatic polyimide leads to a strong interaction between the molecular chains, resulting in poor solubility and melt processability, which severely limits the application of aromatic polyimides $[9,10]$. Since the development of LARC-TPI, a thermoplastic polyimide adhesive, which was developed by NASA research institute in 1980, thermoplastic polyimides have attracted extensive attention [11]. Thermoplastic polyimides can be used as high-temperature adhesives [12, 13] and flexible copper clad plates $[14,15]$ due to their good melt processability and heat resistance.

Traditional polyimide processing is usually accompanied by inefficient cyclization, difficulty in removing moisture, bubbles, uneven film and other problems [16]. Therefore, it is mandatory to improve the processability of polyimide. As is known, flexible groups $[17,18]$, bulky side groups $[19,20]$ and noncoplanar structures $[21,22]$ can be introduced into the molecular chains to reduce the stiffness as well as the mutual interaction between molecular chains to improve the processability or thermoplasticity of polyimides [23-26]. American DuPont company has prepared a series of thermoplastic PIs by introducing a large number of flexible groups into the molecular

${ }^{*}$ Corresponding author, e-mail: hegj@scut.edu.cn (C) BME-PT 
skeleton, but their glass transition temperatures are below $240^{\circ} \mathrm{C}$, therefore they cannot be used in a hightemperature environment [27]. Saeed et al. [28] successfully synthesized two thermoplastic polyimides with 3,4'-ODA and different dianhydrides ODPA and BPDA, whose glass transition temperature were below $250^{\circ} \mathrm{C}$. Besides, Sasaki et al. [29] have developed polyimide by 2,3,3',4'-biphenyltetracarboxylic dianhydride (a-BPDA) for dianhydride, 3,4'-oxydianiline (3,4'-ODA) or 1,3-bis(4-aminophenoxy) benzene (1,3.4-APB) or 1,3-bis(3-aminophenoxy) benzene (APB) for diamine, 2,4-diamino-1-(4-phenylethynylphenoxy) benzene (mPDAp) for the end-capping agent respectively. Moreover, the non-coplanar structure of a-BPDA breaks the regularity of molecular chain, so that the synthesized polyimides have good thermoplasticity, solubility, and higher glass transition temperature. What's more, a series of polyimides with good solubility and thermoplasticity were also prepared by $2,3,3^{\prime}, 4^{\prime}$-oxydiphthalic dianhydride (a-ODPA) and 2,3,3',4'-biphenyltetracarboxylic dianhydride (a-BPDA), 3,4'-oxydianiline (3,4'-ODA) and PEPA [30]. By introducing 2,2-bis [4-(4-aminophenoxy)phenyl] propane (BAPP), Kong et al. [9] successfully synthesized a series of thermoplastic polyimides films for the side methyl structure and ether bond of the molecular chain of BAPP, which improved the melt fluidity of polyimide. PIs with excellent processability inevitably sacrifice their thermal properties, and seeking the balance between excellent processability with good thermal properties has been a long-term existed scientific and technological challenge.

9,9'-bis(4-aminophenyl)fluorene (BAFL) is an aromatic diamine with a rigid molecular skeleton because of its unique fluorenyl cardo groups. However, PI synthesized from a large number of rigid molecular structures is brittle, having difficulty in forming films. Therefore, other diamines with flexible groups can be added in the synthesis process to optimize the performance of the PI, and then the copolymerized polyimide (co-polyimide) can be obtained. Under delicate design, the polymer prepared by copolymerization forms a semi-interpenetrating or interpenetrating network structure to integrate better and balance the influence of each monomer on the polymer, to achieve the purpose of 'customizing' the material performance. Su et al. [31] have developed a 'TriAPI' with good thermal stability and thermoplastic by introducing 3,3',4,4'-benzophenonetetracarboxylic dianhydride (BTDA), 2,2-bis[4-(4-aminophenoxy)phenyl] propane (BAPP) and 4,4'-oxydianiline ternary copolymer (ODA). Based on ternary copolymerization, An et al. [24] prepared PI adhesive which can be partially thermalized at low temperature by introducing 4,4'-oxydiphthalicanhydride (s-ODPA), 9,9'-bis(4-aminophenyl)fluorene (BAFL), and 3,4'-diaminodiphenyl ether (3,4'-ODA), and the glass transition temperature of the adhesive was approximately $340^{\circ} \mathrm{C}$, possessing excellent thermoplasticity and melt fluidity. Besides, Chen et al. [32] successfully prepared a series of PIs with excellent thermal stability and low melt viscosity with 4-phenylethynylphthalic anhydride (4-PEPA), 9,9'bis(4-aminophenyl)fluorene (BAFL), 4-4'-oxydiphthalic anhydride (ODPA).

In this study, quaternary copolyimides were synthesized from asymmetric diahydride: 3,4'-oxydiphthalic anhydride (a-ODPA) and symmetric anhydride: 4,4'-oxydiphthalicanhydride (s-ODPA), 9,9'-bis(4aminophenyl)fluorene (BAFL) and 2,2-bis[4-(4aminophenoxy)phenyl]propane (BAPP) through two-step method. Under the coordination of quaternary copolymerization, a new type of thermoplastic polyimides with excellent processability and thermal stability were prepared through the synergistic effect of non-coplanar structure, fluorenyl cardo groups, methyl groups and flexible ether bonds. A detailed investigation on the structure of monomers and polyimides by Fourier Transform Infrared (FTIR) and proton nuclear magnetic resonance (H-NMR) spectroscopic techniques along with X-ray Diffraction (XRD) analysis. The thermal properties of polyimides were measured by thermogravimetry (TGA), differentialé scanning calorimetry (DSC) and dynamic mechanical analysis (DMA). The results showed that the synergistic effect of non-coplanar structure, fluorenyl cardo groups and flexible groups endowed good heat resistance (high $T_{\mathrm{g}}$ ), excellent thermoplasticity and solubility, which would have great application potential in the fields of microelectronics, aerospace and military industries.

\section{Experiment}

\subsection{Materials}

2,3,3',4'-oxydiphthalic dianhydride (a-ODPA), 4,4'oxydiphthalic anhydride (s-ODPA), 9,9'-bis(4aminophenyl)fluorene (BAFL) and 2,2'-Bis[4-(4aminophenoxy)-pheny]propane (BAPP) were both purchased from Tokyo Chemical Industry Co.,Ltd 


$$
\begin{aligned}
& \text { 2010 } \\
& \text { + } 0 \text { 近" } \\
& y=
\end{aligned}
$$

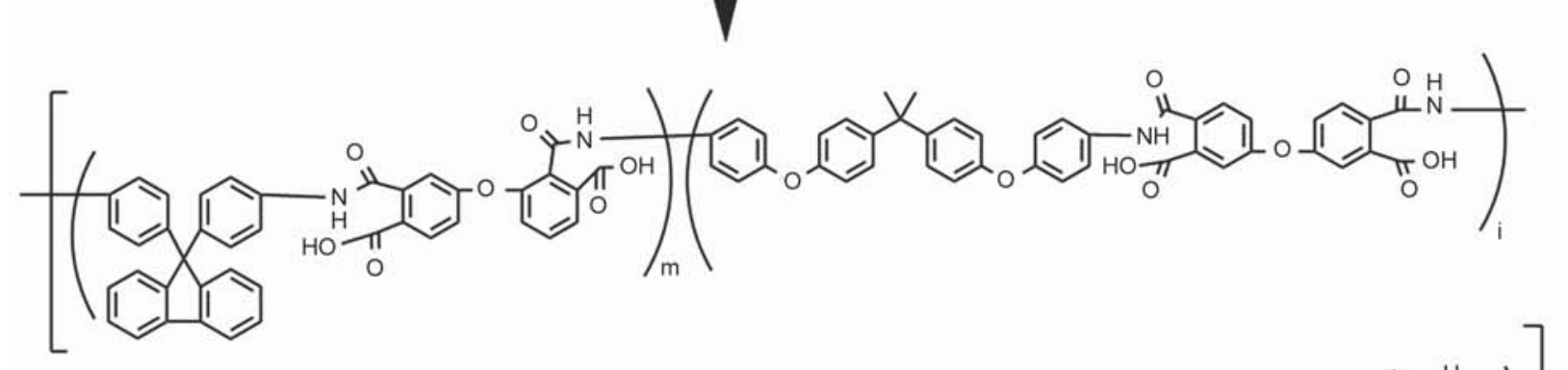

$$
\begin{aligned}
& \text { ther }
\end{aligned}
$$

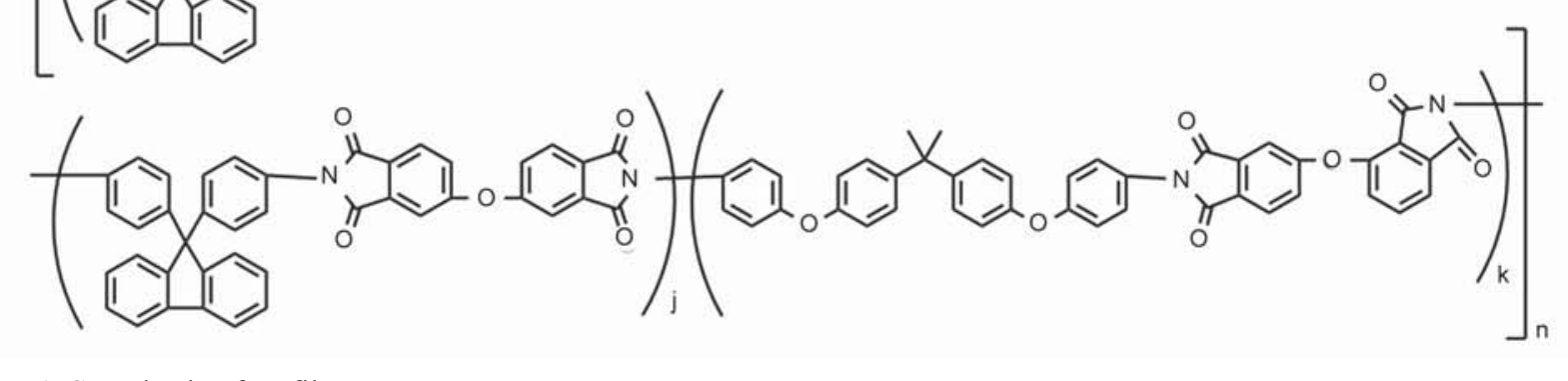


(TCI Shang-hai). The dianhydrides were used after heating to $160^{\circ} \mathrm{C}$ for $5 \mathrm{~h}$ and the diamines were used after heating to $60^{\circ} \mathrm{C}$ for $5 \mathrm{~h}$ in vacuo for drying before use. Their chemical structures are shown in Figure 1. $N, N$-Dimethylacetamide(DMAc), supplied by Sinopharm Chemical Reagent Co.,Ltd,China, was distilled before use.

\subsection{Polymer synthesis}

As shown in Figure 1, PI was synthesized through a two-step method. The monomer content of different molar ratios of PI was shown in Table 1. Before use, BAFL and BAPP were dried in a vacuum oven at $60^{\circ} \mathrm{C}$ for 4 hours, s-ODPA and a-ODPA were dried in a vacuum oven at $160^{\circ} \mathrm{C}$ for 4 hours, and DMAc was stirred and dried over $\mathrm{CaH}_{2}$ for 6 hours. First, BAFL, BAPP and DMAc were placed in a $100 \mathrm{ml}$ three-necked flask and mechanically stirred at room temperature under a nitrogen atmosphere. After the diamine was completely dissolved, the solution was placed in an ice bath, and s-ODPA and a-ODPA were added in three portions. The reaction was carried out for 5 hours in an ice water bath, during which DMAc was added to ensure a complete reaction, making sure that the solid content of the monomer was $15 \mathrm{wt} \%$.

After completion of the reaction, a PAA solution was obtained, and bubbles in the solution were evacuated under vacuum. Then the PAA solution was uniformly coated on a clean glass plate by an automatic film applicator. The sample after the completion of the coating film was placed in a high-temperature blast dryer to obtain a PI film by thermal imidization method: drying at $80,100,150,200,250$, and $300^{\circ} \mathrm{C}$ for one hour. After the glass plate and the PI film were cooled to room temperature, and the glass plate was immersed in a water bath at $45^{\circ} \mathrm{C}$ to remove the PI film from the glass. The obtained PI sample was dried for testing. PI-F presented in this study as a control group.

Table 1. The contents of dianhydrides and diamines in the PI films.

\begin{tabular}{|c|c|c|c|c|}
\hline Sample & a-ODPA & s-ODPA & BAFL & BAPP \\
\hline PI-A & 50 & 50 & 0 & 100 \\
\hline PI-B & 50 & 50 & 10 & 90 \\
\hline PI-C & 50 & 50 & 30 & 70 \\
\hline PI-D & 50 & 50 & 50 & 50 \\
\hline PI-E & 50 & 50 & 70 & 30 \\
\hline PI-F & 0 & 100 & 50 & 50 \\
\hline
\end{tabular}

\subsection{Characterization}

The microstructure of PI was characterized by Fourier-transform infrared (FT-IR) spectroscopy (Nicolet, NEXUS670) with the test range of $400-4000 \mathrm{~cm}^{-1}$, $\mathrm{X}$-ray diffractometry (XRD) (X' Pert3 Powder) over the range of $2-60^{\circ},{ }^{1} \mathrm{H}-\mathrm{NMR}$ spectroscopy (Avance digital 400 spectrometer) at $400 \mathrm{MHz}$ in DMSO- $d_{6}$. The solubility of PI was measured by dissolving $5 \mathrm{mg}$ PI samples in $10 \mathrm{ml}$ of DMF, DMAc, NMP, DMSO, acetone, and THF for $24 \mathrm{~h}$.

Dynamic mechanical thermal analysis (DMA242E Artemis, NETZSCH, Germany) were conducted at a heating rate of $10^{\circ} \mathrm{C} / \mathrm{min}$ from 25 to $350^{\circ} \mathrm{C}$ and a frequency of $1 \mathrm{~Hz}$ in nitrogen. The dimensions of the PI samples were $50 \mathrm{~mm} \times 5 \mathrm{~mm} \times 0.028 \mathrm{~mm}$.

Differential scanning calorimetry analyses (DSC) were performed on DSC204, Netzsch, Germany in a nitrogen atmosphere at $30-350^{\circ} \mathrm{C}$ at the heating rate of $10 \mathrm{~K} / \mathrm{min}$.

Thermogravimetric analysis (TGA) was performed on TG209, Netzsch, Germany to measure its thermal stability under a nitrogen atmosphere at $30-800^{\circ} \mathrm{C}$ at a heating rate of $10 \mathrm{~K} / \mathrm{min}$.

The molecular weight and its distribution (MWD) were determined by multi-detector gel permeation chromatography (Waters 1515; Waters corporation, America), using DMF as the eluent at a flow rate of $1.0 \mathrm{ml} / \mathrm{min}$ at $25^{\circ} \mathrm{C}$.

\section{Results and discussion}

\subsection{Structure characterization}

As shown in Figure 1, a series of different PI films (PI-A PI-F) were synthesized by a two-step method. Subsequently, the chemical structure of PI films was characterized by FTIR spectra and ${ }^{1} \mathrm{H}-\mathrm{NMR}$ spectra. The typical FTIR spectra curve of polyimide was shown in Figure 2, and the presence of imide groups was confirmed by the characteristic absorption peaks at $1778,1727,1379,1242$ and $744 \mathrm{~cm}^{-1}$. As we know, the characteristic absorption peaks at 1778 and $1727 \mathrm{~cm}^{-1}$ corresponded to asymmetric and symmetric stretching vibration absorption peaks of $\mathrm{C}=\mathrm{O}$ bond, respectively, and $1379 \mathrm{~cm}^{-1}$ was a stretching vibration absorption peak of $\mathrm{C}-\mathrm{N}$ bond. Furthermore, $1242 \mathrm{~cm}^{-1}$ was a stretching vibration absorption peak of the $\mathrm{C}-\mathrm{O}-\mathrm{C}$ bond, and $744 \mathrm{~cm}^{-1}$ represents a bending vibration absorption peak of the imide ring. The appearance of the above characteristic absorption peaks indicates that PI-A PI-F had been successfully synthesized. A typical ${ }^{1} \mathrm{H}-\mathrm{NMR}$ 


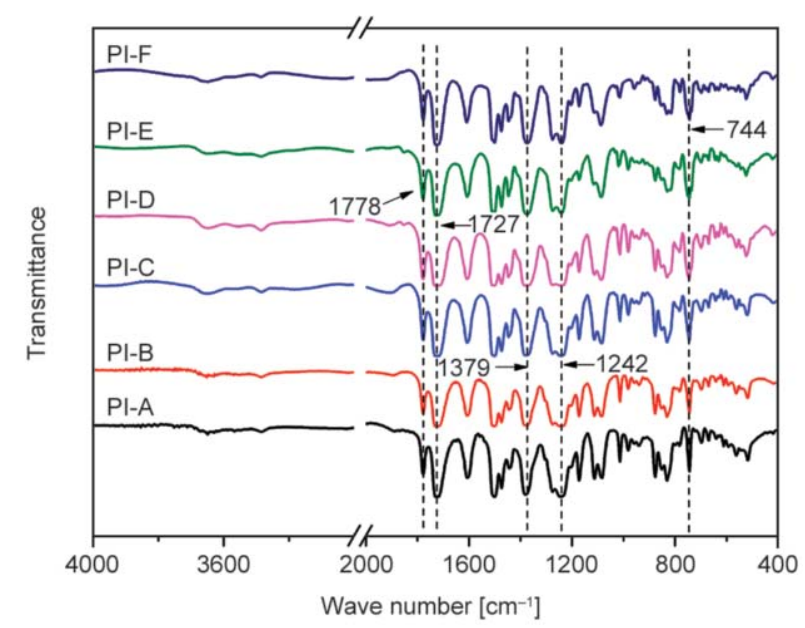

Figure 2. FTIR spectra of PI films.

spectrum of PI-A PI-E was shown in Figure 3. There were obvious differences between PI-A and PI-B PI-E. In the curve of PI-B PI-E, a significant nuclear magnetic resonance peak appeared in the range of 7.30-7.38 ppm, which was attributed to the fluorenyl cardo groups of BAFL. In addition, the
Table 2. Absolute molecular weights of PI-A PI-E.

\begin{tabular}{|c|c|c|c|c|c|}
\hline Sample & PI-A & PI-B & PI-C & PI-D & PI-E \\
\hline$M_{\mathrm{n}} \quad\left[\mathrm{g} \cdot \mathrm{mol}^{-1}\right]$ & 60883 & 87641 & 57272 & 54146 & 43028 \\
\hline$M_{\mathrm{w}} \quad\left[\mathrm{g} \cdot \mathrm{mol}^{-1}\right]$ & 107021 & 164878 & 124820 & 113223 & 77823 \\
\hline $\mathrm{PDI}^{\mathrm{a}}$ & 1.8 & 1.9 & 2.2 & 2.1 & 1.8 \\
\hline
\end{tabular}

$M_{\mathrm{n}}$ : number average molecular weight;

$M_{\mathrm{w}}$ : weight average molecular weight;

PDI: polydispersity index. $\mathrm{PDI}^{\mathrm{a}}=M_{\mathrm{w}} / M_{\mathrm{n}}$

appearance of other nuclear magnetic resonance hydrogen peaks further confirmed the successful synthesis of PI films.

In Table 2 the absolute molecular weights of the PI films (PI-A PI-E) measured by GPC were listed, which indicated that the prepared PI film reached high molecular weight. The molecular weights of the PI films were measured by GPC as shown in Figure 4. The GPC results showed a significant single peak and the retention time before the major molecular weight peaks increased as the increasing content of BAFL. This phenomenon confirmed that the PI

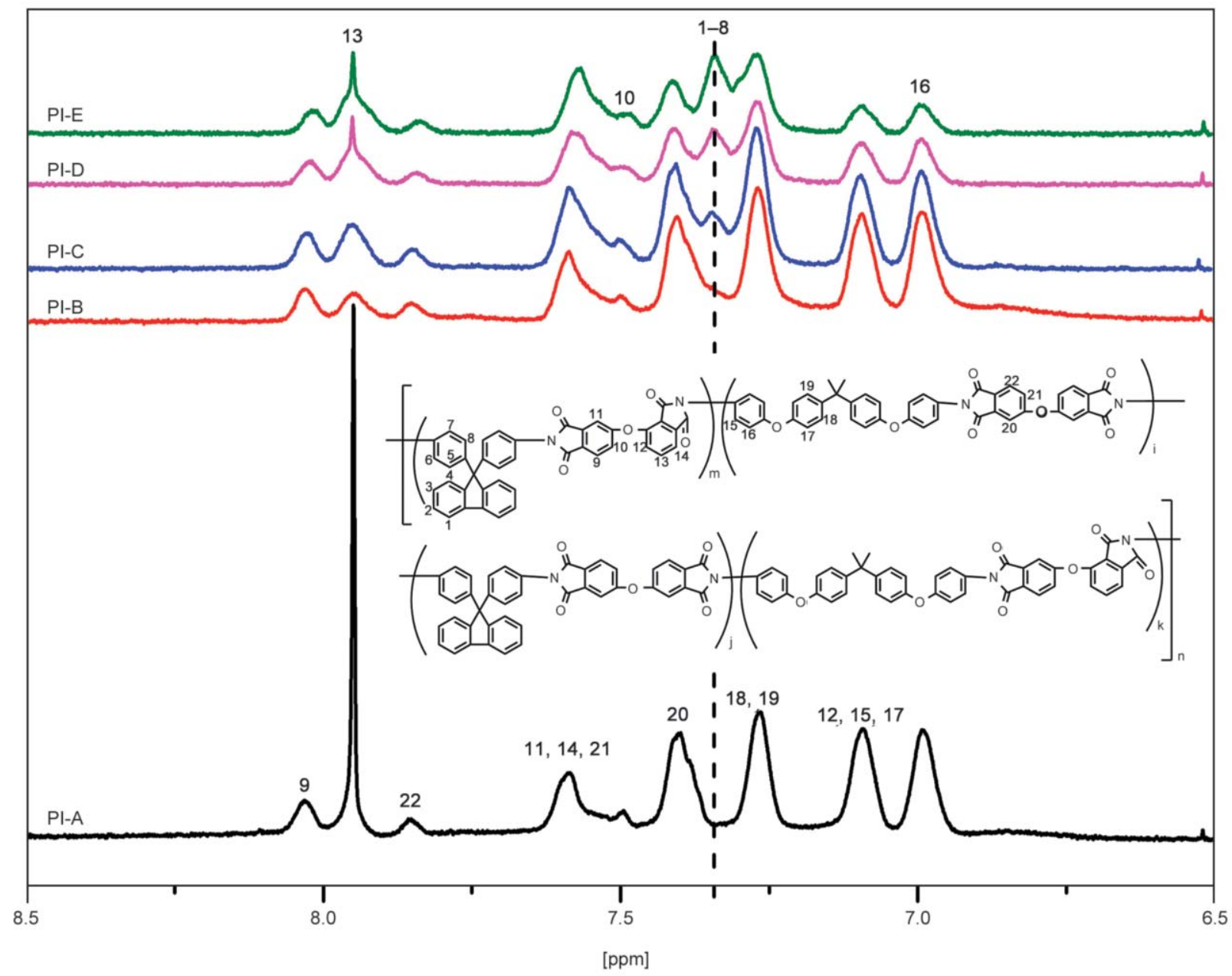

Figure 3. ${ }^{1} \mathrm{H}-\mathrm{NMR}$ spectra of the PI films in DMSO- $d_{6}$. 


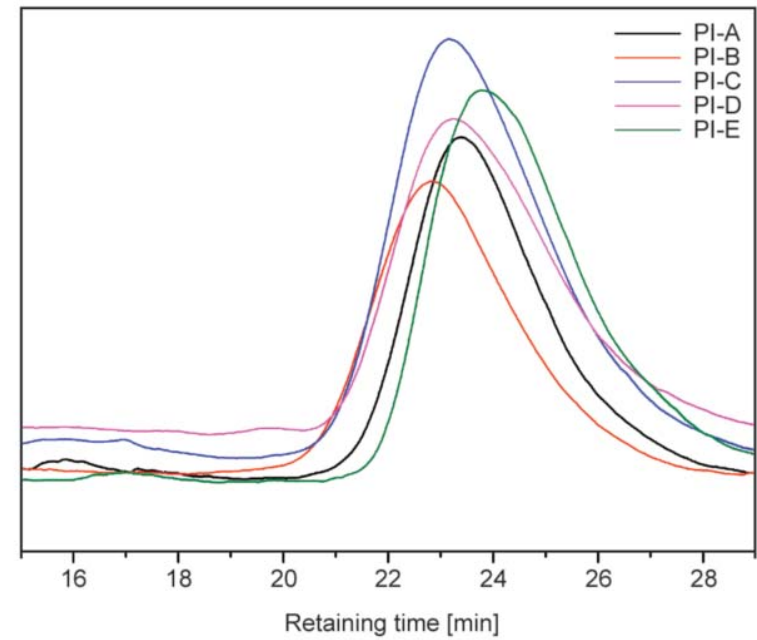

Figure 4. GPC curves of the PI films.

films were stick copolymers and the introduction of BAFL reduced the molecular weight of PI, which may be attributed to the bulky fluorenyl cardo groups of BAFL.

\subsection{Solubility}

The presence of a large number of benzene rings and five-membered imide rings in the molecular chain of polyimide formed a large $\pi$ bond system, which ensured the regularity of the molecular chain of the PI and greatly increased the interaction between the molecular chains, making the molecular chain difficult to stretch and leading to poor solubility and melt processability of the PI. However, the existence of non-coplanar structures would break the regularity of the molecular chain and destroy the $\pi$ bond in the PI molecular chain; the methyl group would also increase the distance between the molecular chains and reduce the molecular interactions of the PI, thereby increasing the solubility of PI.

Table 3 showed the solubility of PI films in various industrial polar aprotic solvents, and PI was completely insoluble in acetone. PI-A PI-E could be completely dissolved in DMF, DMAc, and NMP within 3 hours at room temperature. After 24 hours at room temperature, only PI-D and PI-E were partially dissolved in DMSO, and PI-A PI-E was partially dissolved in THF, and the solubility increased with the increasing content of BAFL, PI-E almost completely dissolved in THF. Besides, we have found that partially dissolved or insoluble PI became completely soluble after heating, for example: PI-D and PI-E were completely dissolved in DMSO after
Table 3. The solubility of PI films in different solvents.

\begin{tabular}{|c|c|c|c|c|c|c|}
\hline Sample & DMF & DMAc & NMP & DMSO & Acetone & THF \\
\hline PI-A & ++ & ++ & ++ & - & - & + \\
\hline PI-B & ++ & ++ & ++ & - & - & + \\
\hline PI-C & ++ & ++ & ++ & - & - & + \\
\hline PI-D & ++ & ++ & ++ & + & - & + \\
\hline PI-E & ++ & ++ & ++ & + & - & + \\
\hline PI-F & + & - & - & - & - & - \\
\hline $\begin{array}{l}++: \\
+: \\
-: \\
\text { DMF: } \\
\text { DMAc: } \\
\text { NMP: } \\
\text { DMSO: } \\
\text { THF: }\end{array}$ & $\begin{array}{l}\text { Complet } \\
\text { artially } \\
\text { nsoluble } \\
\text { V,N-Dim } \\
\text { V,N-Dim } \\
\text { V-Methy } \\
\text { Dimethy } \\
\text { Cetrahyd }\end{array}$ & $\begin{array}{l}\text { ly soluble } \\
\text { oluble; } \\
\text { thylform } \\
\text { pyylaceta } \\
\text { sulfoxide } \\
\text { ofuran. }\end{array}$ & $\begin{array}{l}\text { mide; } \\
\text { nide; } \\
\text { ne; }\end{array}$ & temperat & are within & 4 hours \\
\hline
\end{tabular}

heating at $60^{\circ} \mathrm{C}$ for 3 hours. The above experimental phenomenon indicated that this series of PI had excellent solubility. The excellent solubility was attributed to the effect of the non-planar structures of aODPA, which broke the regularity of the molecular chains and decreased inter-molecular interactions. In addition, the methyl groups of BAPP and the large fluorenyl cardo groups of BAFL also greatly increased the distance between the molecular chains Finally, the flexible ether bonds in a-ODPA, s-ODPA and BAPP also improved the flexibility of molecular chains. The synergistic effect of them made the PI films had excellent solubility. It can be seen from Table 3 that PI-F was only partially dissolved in DMF solvent. This phenomenon indicated that the solubility of PI-F was poor. This was because a large number of s-ODPA and BAFL improved the rigidity of the PI-F molecular chain, which made the molecular chains stack tightly. The control experiment of PI-F further illustrated the contribution of the non-coplanar structure of a-ODPA to the excellent solubility of PI-A PI-E, and also showed that the synergistic effect of each monomer group under the control of quaternary copolymerization endowed PI-A PI-E excellent solubility.

The detailed X-ray diffraction patterns of the PI films were shown in Figure 5. It is observed that there was no crystalline phase and only a broad peak in the XRD patterns, which demonstrated the amorphous structures of PI films. This result proved that the noncoplanar structure destroyed the regularity of the PI molecular chains, and furthermore, the non-coplanar structure and loosed molecular chain stack greatly increased the solubility of PI films. 


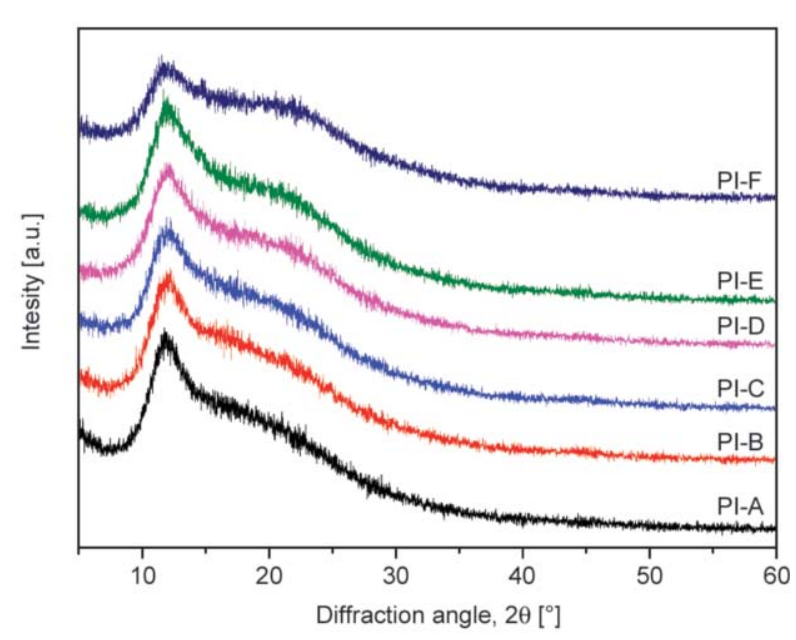

Figure 5. X-ray diffraction patterns of the PI films.

\subsection{Thermal properties}

Due to its excellent properties, polyimide was used in a wide range of fields, and thermal properties were one of the most important factors for polyimide. Introducing bulky side groups and cross-linkers is an

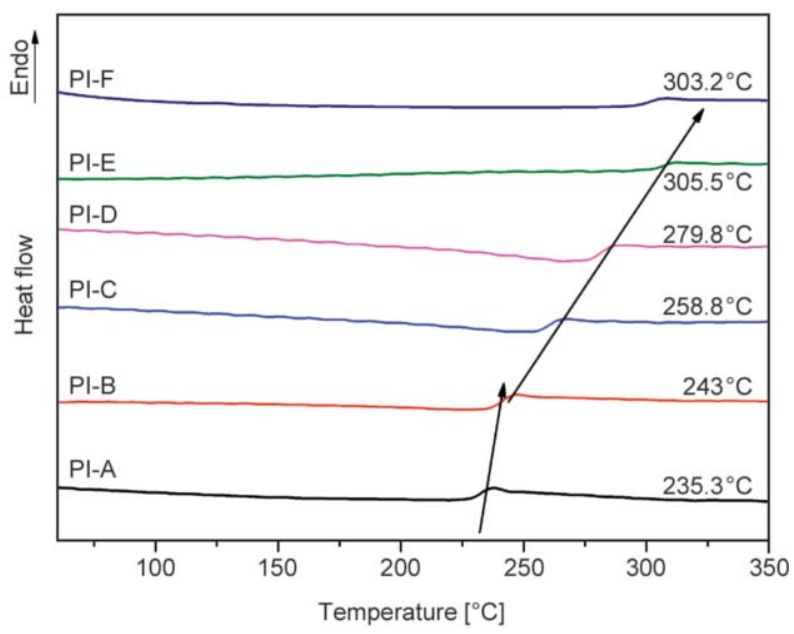

Figure 6. DSC patterns of the PI films.

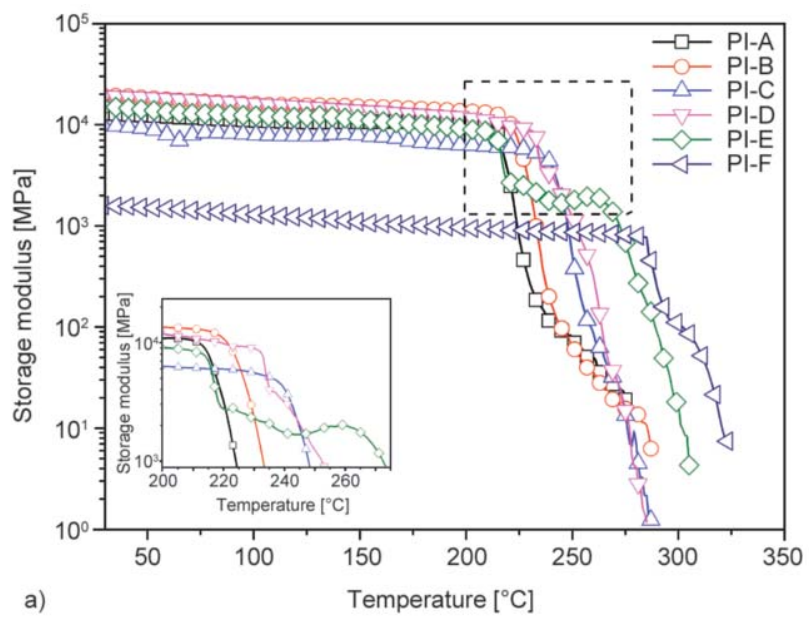

Table 4. Thermal properties of the PI films.

\begin{tabular}{|c|c|c|c|c|c|}
\hline \multirow[b]{2}{*}{ Sample } & \multicolumn{3}{|c|}{ TGA } & \multirow{2}{*}{$\begin{array}{c}\text { DSC } \\
T_{g}{ }^{\prime} \\
{\left[{ }^{\circ} \mathbf{C}\right]}\end{array}$} & \multirow{2}{*}{$\begin{array}{c}\text { DMA } \\
T_{\mathrm{g}}{ }^{\prime \prime} \\
{\left[{ }^{\circ} \mathrm{C}\right]}\end{array}$} \\
\hline & $\begin{array}{l}\boldsymbol{T}_{\mathrm{d} 5 \%} \\
{\left[{ }^{\circ} \mathrm{C}\right]}\end{array}$ & $\begin{array}{c}T_{\mathrm{d} 10 \%} \\
{\left[{ }^{\circ} \mathrm{C}\right]}\end{array}$ & $\begin{array}{c}R_{800}{ }^{\circ} \mathrm{C} \\
{[\%]}\end{array}$ & & \\
\hline PI-A & 502.8 & 514.3 & 51.08 & 235.3 & 227.7 \\
\hline PI-B & 507.1 & 517.7 & 51.54 & 243.0 & 237.5 \\
\hline PI-C & 513.8 & 525.0 & 56.23 & 258.8 & 258.0 \\
\hline PI-D & 513.0 & 526.9 & 57.43 & 279.8 & 261.4 \\
\hline PI-E & 518.4 & 536.6 & 60.08 & 305.5 & 293.8 \\
\hline PI-F & 523.0 & 536.2 & 58.97 & 303.2 & 301.3 \\
\hline
\end{tabular}

effective way to increase the thermal properties of the polymer, which hinders the mobility of the polymer chain [33]. The DSC test curve of PI films was shown in Figure 6. It was evident that there was no crystal absorption peak of the PI film in the range of test temperature. Besides, a significant step in the endothermic direction occurred above $230^{\circ} \mathrm{C}$. This step could represent the glass transition temperature of the PI, as shown in Table 4. From PI-A PI-E, $T_{\mathrm{g}}$ gradually increased from 235.3 to $305.5^{\circ} \mathrm{C}$ with the increasing content of BAFL in the PI, indicating that the addition of BAFL greatly improved the glass transition temperature of PI. However, the $T_{\mathrm{g}}$ of PI-F was $303.2^{\circ} \mathrm{C}$. Comparing PI-F with PI-D, it was evident that with the addition of a-ODPA, the $T_{\mathrm{g}}$ of PI-D had decreased. This was because the non-coplanar molecular structure of a-ODPA destroyed the regularity and reduced the stacking density of molecular chains, which improved the flexibility of PI molecular chains. Besides, to further verify the glass transition temperature of PI, the test result curve of DMA was shown in Figure 7, wherein the temperature corresponding to the peak of the loss angle (Figure 7b) was defined as the glass transition temperature of PI.

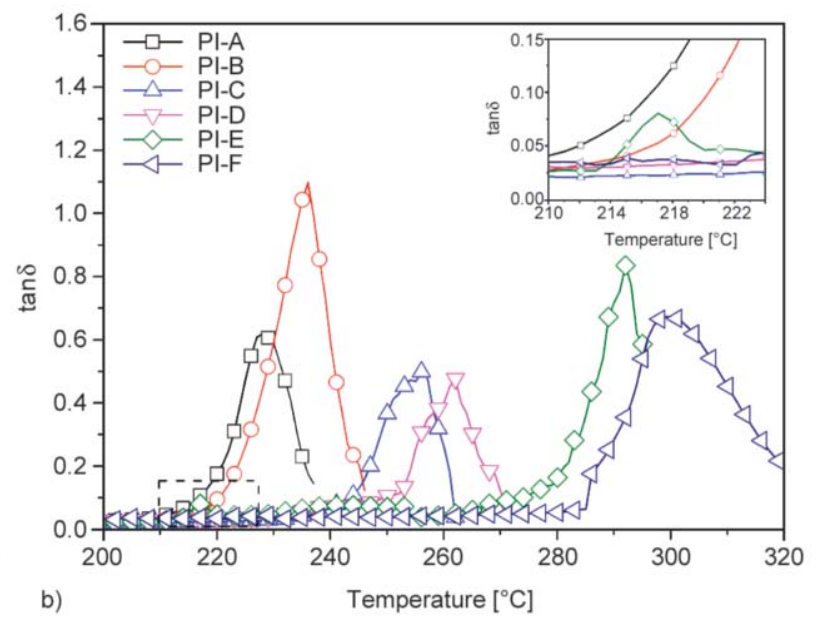

Figure 7. DMA curves of the PI films: (a) storage modulus and (b) $\tan \delta$. 
As can be seen from Table 4, the glass transition temperature of the PI films obtained by the DMA test was slightly lower than the glass transition of the PI films obtained by the DSC test. As shown in Figure $7 \mathrm{~b}$, from PI-A PI-E, the $T_{\mathrm{g}}$ of PI gradually increased from 227.7 to $293.8^{\circ} \mathrm{C}$. It was evident that PI with more content of BAFL had a higher $T_{\mathrm{g}}$, which was attributed to the molecular chain structure of PI. The addition of BAFL introduced bulky fluorenyl cardo groups. The presence of fluorenyl cardo groups greatly restricted the movement between molecular chains, and the energy required for the molecular chain to 'unfreeze' was significantly increased. In addition, it was surprising that in the $\tan \delta$ curve (Figure 7b), PI-E showed two peaks at 217 and $293.8^{\circ} \mathrm{C}$, respectively, and the two peaks also corresponded to two sharp reduction platforms in the storage modulus curve (Figure $7 \mathrm{a}$ ), this phenomenon may be due to the excessive content of BAFL, leading PI-E forms a block structure. Combining the GPC curve of Figure 4 with the DSC curve of Figure 6 , it could be known that there was only one distinct peak in the GPC curve, and there was only one transition platform in the DSC curve. This phenomenon strongly confirmed that PI-E was a block copolymer due to the presence of excessive BAFL [34]. In summary, although the $T_{\mathrm{g}}$ obtained by DSC and DMA test was slightly different, the two results showed the same growth trend: when the content of a-ODPA and s-ODPA were fixed, as the content of BAFL increased, the glass transition temperature of the PI increased, which was attributed to the bulky fluorenyl cardo groups of the BAFL.

The typical TGA curve of PI was shown in Figure 8. It could be seen that all PI films exhibit a single-step thermal degradation curve, indicating that they had the same thermal decomposition process. From PI-A PI-E, the temperatcure corresponding to 5\% of the thermal weight loss gradually increased, and $T_{\mathrm{d} 5 \%}$ was greater than $500^{\circ} \mathrm{C}$ (specific temperature was shown in Table 4), wherein the thermal decomposition temperature of PI-E was $518.4^{\circ} \mathrm{C}$. Besides, the residual mass of PI was greater than $51 \%$ at $800^{\circ} \mathrm{C}$. This phenomenon was also attributed to the bulky fluorenyl cardo groups of BAFL. The presence of bulky fluorenyl cardo groups significantly increased the rigidity of the molecular chain. What's more, the $T_{\mathrm{d} 5 \%}$ of PI-F was $523^{\circ} \mathrm{C}$, which was attributed to the regular benzene rings and the bulky fluorenyl cardo groups in PI-F, but strong, rigid groups

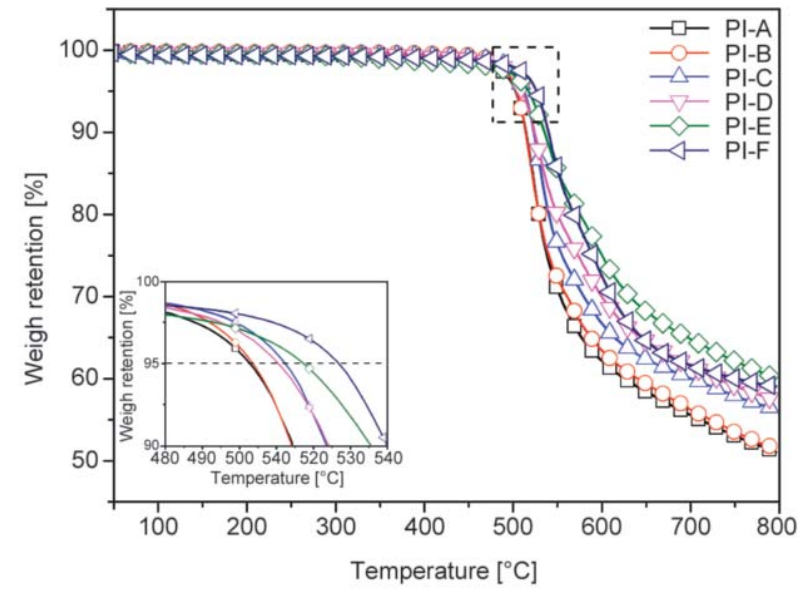

Figure 8. TGA curves of the PI films.

led to extremely poor solubility of PI-F. The TGA test results showed that the series of PI films had excellent thermodynamic properties and could be widely used in various fields.

\subsection{Thermoplastic properties}

Most of the traditional polyimide materials were insoluble and difficult in melt processability, so synthesizing thermoplastic polyimide was an important step in advancing the application of polyimide materials. However, most of the thermoplastic polyimides in the current research had low glass transition temperature and narrower application fields. The key problem in the thermoplastic polyimide area was to improve the thermoplasticity of polyimide without reducing or even increasing their heat resistance. DMA test was one of the most effective test methods to reflect the thermoplasticity of materials. According to the free volume theory, when the material reaches its glass transition temperature, the free volume in the molecular chain is 'unlocked', the molecular segment begins to move, the molecular conformation is continually changing, the storage modulus drops significantly, and the material can be thermally processed in this state. It could be seen from Figure $7 \mathrm{a}$ that when the temperature reaches $T_{\mathrm{g}}$, the storage modulus dropped significantly. This was because as the temperature rises, the free volume between molecules increased. When the temperature of PI films (PI-A PI-E) was close to the glass transition temperature $\left(T_{\mathrm{g}}\right)$, their storage modulus dropped sharply and the drop value was above $10^{4} \mathrm{MPa}$, which indicated that the synthesized PI films showed excellent thermoplasticity $[18,23]$. Besides, there were two sharp reduction platforms for the storage 
modulus of PI-E in Figure 7a. It was because that the excessive addition of BAFL lead to a special block structure of PI-E. However, compared with PI-A PI-E, the dropped amplitudes of the storage modulus of PI-F near $T_{\mathrm{g}}$ were only $10^{3} \mathrm{MPa}$, which was much lower than PI-A PI-E. This phenomenon further indicated that under quaternary copolymerization, the introduction of a-ODPA greatly improved the storage modulus of PI-A PI-E before $T_{\mathrm{g}}$, and with the twist non-coplanar structure of a-ODPA, the molecular chains of PI had more room for movement when the temperature near $T_{\mathrm{g}}$, which endowed them excellent thermoplasticity. Besides, the introduction of the fluorenyl cardo groups contained in BAFL and the methyl groups in BAPP increased the distance between the PI molecular chains, which was another reason for the significant decrease in the storage modulus of PI when the temperature near $T_{\mathrm{g}}$. Finally, the presence of flexible ether linkages in BAPP and a-ODPA and s-ODPA also increased the flexibility of the PI molecular skeleton, so the PI films showed excellent thermoplasticity under the three conditions.

\section{Conclusions}

A series of novel quaternary copolymerization thermoplastic polyimide films were successfully prepared by two-step method with asymmetric diahydride: 3,4'-oxydiphthalic anhydride (a-ODPA) and symmetric anhydride: 4,4'-oxydiphthalicanhydride (s-ODPA), and 9,9'-bis(4-aminophenyl)fluorene (BAFL), 2,2-bis[4-(4-aminophenoxy)phenyl]propane (BAPP) as diamine. The experimental results showed that the large fluorenyl cardo groups of BAFL, the non-coplanar structure in a-ODPA, and the side methyl group of BAPP significantly increased the distance between molecular chains and reduced the interaction between PI molecular chains. The solubility and melt processability (thermoplasticity) of PI films were significantly improved. Besides, the large fluorenyl cardo groups of BAFL greatly enhanced the rigidity of the molecular skeleton, which significantly increased the heat resistance of polyimide. The thermal decomposition temperature of PI-A PI-E was above $500^{\circ} \mathrm{C}$, and their glass transition temperature $\left(T_{\mathrm{g}}\right)$ was in the range of 235.3 $305.5^{\circ} \mathrm{C}$. This series of quaternary copolymerization thermoplastic polyimide combined excellent heat resistance and thermoplasticity with excellent solubility to ensure excellent processing performance of PI.
This series of PIs would have great application potential in the fields of microelectronics, aerospace and military industry.

\section{Acknowledgements}

The authors are grateful for the financial support from the National Key R\&D Program of China (No. 2016YFB0302000)

\section{References}

[1] Suzuki K., Youn S-W., Hiroshima H., Takagi H.: Nanopatterning on soluble block copolymer polyimide by nanoimprint. Japanese Journal of Applied Physics, 54, 088002/1-088002/3 (2015).

https://doi.org/10.7567/jjap.54.088002

[2] Lin C. H., Wong T. I., Wang M. W., Chang H. C., Juang T. Y.: Synthesis of diallyl-containing polyimide and the effect of allyl groups on properties. Journal of Polymer Science Part A: Polymer Chemistry, 53, 513-520 (2015). https://doi.org/10.1002/pola.27459

[3] Qiu G., Ma W., Jiao Y., Wu L.: Low-dielectric-constant aromatic homopolyimide and copolyimide derived from pyromellitic dianhydride, 4,4'-oxydianiline, 2,2bis[4-(4-aminephenoxy)phenyl]propane, 1,4-bis(4aminophenoxy)benzene, or 1,3-bis(4-aminophenoxy) benzene. Journal of Applied Polymer Science, 136, 47405/1-47405/10 (2019).

https://doi.org/10.1002/app.47405

[4] Köytepe S., Küçük İ., Seçkin T., Adigüzel H. İ.: Preparation, characterization, and properties of novel polyimide- $\mathrm{SiO}_{2}$ hybrid composites based on bipyridine for low dielectric applications. Polymer-Plastics Technology and Engineering, 54, 1251-1262 (2015). https://doi.org/10.1080/03602559.2015.1010216

[5] Kim J., Kwon J., Kim M., Do J., Lee D., Han H.: Lowdielectric-constant polyimide aerogel composite films with low water uptake. Polymer Journal, 48, 829-834 (2016). https://doi.org/10.1038/pj.2016.37

[6] Jain N., Tripathi S. K., Nasim M.: Preparation and characterization of aminopropylsilatrane endcapped polyimide films. International Journal of Polymeric Materials and Polymeric Biomaterials, 63, 178-184 (2014). https://doi.org/10.1080/00914037.2013.812089

[7] Dobrzynska J. A., Joris P., Jiguet S., Renaud P., Gijs M. A. M.: Polyimide foam-like microstructures: Technology and mechanical properties. Journal of Micromechanics and Microengineering, 21, 105016/1-105016/12 (2011). https://doi.org/10.1088/0960-1317/21/10/105016

[8] Jena K. K., Narayan R., Raju K. V. S. N., Rout T. K.: TEM, XPS and thermo-mechanical properties of novel sustainable hybrid coatings. Progress in Organic Coatings, 78, 140-145 (2015).

https://doi.org/10.1016/j.porgcoat.2014.09.014 
[9] Kong C., Zhang Q., Gu X., Chen D.: Synthesis, structures and properties of polyimide based on 2,2'-bis(4aminophenoxy phenyl) propane. Journal of Macromolecular Science Part A: Pure and Applied Chemistry, 43, 1825-1833 (2006).

https://doi.org/10.1080/10601320600941086

[10] Wang K., Yang S. Y., Fan L., Zhan M. S., Liu J. G.: Preparation and properties of molecular-weight-controlled polyimides derived from 1,4-bis(4'-amino-2'-trifluoromethylphenoxy)benzene and 4,4'-oxydiphthalic anhydride. Journal of Polymer Science Part A: Polymer Chemistry, 44, 1997-2006 (2006).

https://doi.org/10.1002/pola.21309

[11] Progar D. J., Clair T. L.: Adhesive bonding study of amorphous LARC ${ }^{\text {TM}}$-TPI. Journal of Adhesion Science and Technology, 8, 67-83 (1994).

https://doi.org/10.1163/156856194x00069

[12] Saeed M. B., Zhan M-S.: Adhesive strength of nanosize particles filled thermoplastic polyimides. Part-I: Multi-walled carbon nano-tubes (MWNT)-polyimide composite films. International Journal of Adhesion and Adhesives, 27, 306-318 (2007).

https://doi.org/10.1016/j.ijadhadh.2006.06.001

[13] Saeed M., Zhan M-S.: Adhesive strength of nano-size particles filled thermoplastic polyimides. Part-II: Aluminum nitride (AIN) nano-powder-polyimide composite films. International Journal of Adhesion and Adhesives, 27, 319-329 (2007).

https://doi.org/10.1016/j.ijadhadh.2006.06.002

[14] Hwang S-M., Lim J-H., Lee C-M., Park E-C., Choi J-H., Joo J., Lee H-J., Jung S-B.: Fabrication of two-layer flexible copper clad laminate by electroless-Cu plating on surface modified polyimide. Transactions of Nonferrous Metals Society of China, 19, 970-974 (2009). https://doi.org/10.1016/s1003-6326(08)60388-x

[15] Hasegawa M., Kaneki T., Tsukui M., Okubo N., Ishii J.: High-temperature polymers overcoming the trade-off between excellent thermoplasticity and low thermal expansion properties. Polymer, 99, 292-306 (2016). https://doi.org/10.1016/j.polymer.2016.07.010

[16] Liaw D-J., Wang K-L., Huang Y-C., Lee K-R., Lai JY., Ha C-S.: Advanced polyimide materials: Syntheses, physical properties and applications. Progress in Polymer Science, 37, 907-974 (2012).

https://doi.org/10.1016/j.progpolymsci.2012.02.005

[17] Ma L., Zhu G., Liu C., Qu C., Jia H., Li L., Cao Z., Hui Z.: Synthesis, characterization, and properties of thermoplastic polyimides derived from 4,4'-(hexafluoroisopropylidene)diphthalic anhydride in diethylene glycol dimethyl ether. High Performance Polymers, 30, 1075 1083 (2017).

https://doi.org/10.1177/0954008317737823

[18] Zhang C., Su G., Chen H., Sun Y., Song H., Tong L.: Synthesis of polyimides with low viscosity and good thermal properties via copolymerization. Journal of Applied Polymer Science, 132, 41303/1-41303/5 (2015). https://doi.org/10.1002/app.41303
[19] Miyauchi M., Ishida Y., Ogasawara T., Yokota R.: Novel phenylethynyl-terminated PMDA-type polyimides based on KAPTON backbone structures derived from 2-phenyl-4,4'-diaminodiphenyl ether. Polymer Journal, 44, 959-965 (2012).

https://doi.org/10.1038/pj.2012.19

[20] Zhou D., Yuan L., Hong W., Zhang H., Hu A., Yang S.: Molecular design of interpenetrating fluorinated polyimide network with enhanced high performance for heat-resistant matrix. Polymer, 173, 66-79 (2019).

https://doi.org/10.1016/j.polymer.2019.04.034

[21] Ni H., Zhang X., Liu J., Yang S.: Intrinsically heat-sealable polyimide films derived from 2,3,3',4'-oxydiphthalic anhydride and aromatic diamines with various ether linkages. High Performance Polymers, 29, 362371 (2017).

https://doi.org/10.1177/0954008316645170

[22] Ni H., Liu J., Yang S.: Preparation and characterization of inherently heat-sealable polyimides with high glass transition temperatures. Journal of Applied Polymer Science, 133, 43058/1-43058/9 (2016).

https://doi.org/10.1002/app.43058

[23] Zhang X. M., Xiao X., Wu X., Liu J. G.: Preparation and properties of heat-sealable polyimide films with comparable coefficient of thermal expansion and good adhesion to copper matrix. Express Polymer Letters, 11, 983-990 (2017).

https://doi.org/10.3144/expresspolymlett.2017.93

[24] An H-Y., Zhan M-S., Wang K.: Synthesis and properties of fluorene-based polyimide adhesives. Polymer Engineering and Science, 51, 1533-1540 (2011). https://doi.org/10.1002/pen.21706

[25] Ratta V., Ayambem A., McGrath J., Wilkes G.: Crystallization and multiple melting behavior of a new semicrystalline polyimide based on 1,3-bis(4-aminophenoxy)benzene (TPER) and 3,3',4,4'-biphenonetetracarboxylic dianhydride (BTDA). Polymer, 42, 6173-6186 (2001). https://doi.org/10.1016/s0032-3861(01)00010-6

[26] Hasegawa M., Sensui N., Shindo Y., Yokota R.: Structure and properties of novel asymmetric biphenyl type polyimides. Homo- and copolymers and blends. Macromolecules, 32, 387-396 (1999).

https://doi.org/10.1021/ma9808629

[27] Kanakarajan K., Kreuz J. A.: Flexible multi-layer polyimide film laminates and preparation thereof. U.S. Patent 5298331A, USA (1994).

[28] Saeed M. B., Zhan M-S.: Effects of monomer structure and imidization degree on mechanical properties and viscoelastic behavior of thermoplastic polyimide films. European Polymer Journal, 42, 1844-1854 (2006). https://doi.org/10.1016/j.eurpolymj.2006.03.004

[29] Sasaki T., Moriuchi H., Yano S., Yokota R.: High thermal stable thermoplastic-thermosetting polyimide film by use of asymmetric dianhydride (a-BPDA). Polymer, 46, 6968-6975 (2005). https://doi.org/10.1016/j.polymer.2005.06.052 
[30] Yu P., Wang Y., Yu J., Zhu J., Hu Z.: Influence of different ratios of a-ODPA/a-BPDA on the properties of phenylethynyl terminated polyimide. Journal of Polymer Research, 25, 110/1-110/11 (2018).

https://doi.org/10.1007/s10965-018-1508-4

[31] Su X., Xu Y., Li L., Song C.: Characterization and thermal degradation kinetics of thermoplastic polyimide based on BAPP. High Performance Polymers, 30, 787 793 (2018).

https://doi.org/10.1177/0954008317729741

[32] Chen W., Ji M., Yang S-Y.: High thermal stable polyimide resins derived from phenylethynyl-endcapped fluorenyl oligoimides with low melt viscosities. Chinese Journal of Polymer Science, 34, 933-948 (2016). https://doi.org/10.1007/s10118-016-1813-5
[33] Zhao H., She W., Shi D., Wu W., Zhang Q-C., Li R. K. Y.: Polyurethane/POSS nanocomposites for superior hydrophobicity and high ductility. Composites Part B: Engineering, 177, 107441/1-107441/8 (2019). https://doi.org/10.1016/j.compositesb.2019.107441

[34] Li Z., Chen J., Zou G., Zhang T., Wei D., Xu X., Guan Y., Zheng A.: A controlled synthesis method of alkyl methacrylate block copolymers via living anionic polymerization at ambient temperature. RSC Advances, 9, 16049-16056 (2019). https://doi.org/10.1039/c9ra01577a 